\title{
Preoperative measurements on MRI in Chiari 1 patients fail to predict outcome after decompressive surgery
}

\author{
Miro-Pekka Jussila ${ }^{1} \cdot$ Juho Nissilä ${ }^{1}$ • Minna Vakkuri ${ }^{2} \cdot$ Päivi Olsén $^{3}$ - Jaakko Niinimäki ${ }^{1}$ • Ville Leinonen ${ }^{4}$. Willy Serlo ${ }^{3}$. \\ Niina Salokorpi ${ }^{2} \cdot$ Maria Suo-Palosaari $^{1}$ (D)
}

Received: 12 January 2021 / Accepted: 30 March 2021 / Published online: 11 May 2021

(C) The Author(s) 2021

\begin{abstract}
Background The purpose of our study was to research the parameters of magnetic resonance imaging (MRI) that would predict the outcome of surgery in patients with Chiari 1 malformation (CM1) and to evaluate changes in MRI parameters after surgery. Methods Fifty-one patients (19 children, 13 adolescents, and 19 adults) operated on due to CM1 in Oulu University Hospital between 2004 and 2018 were evaluated. Seventeen parameters were measured from the preoperative MRI and 11 from the postoperative MRI. The correlations between the MRI parameters and the clinical variables before and after surgery were analyzed.

Results The majority ( $88.2 \%$ ) of the patients had favorable surgical outcomes. Postoperatively, subjective symptoms improved in $88.6 \%$ of the patients and syringomyelia in $81.8 \%$. The location of the cerebellar tonsils, when measured in relation to the $\mathrm{C} 2$ synchondrosis or the end plate, postoperatively moved cranially in $51.0 \%(n=26)$, did not change in $27.4 \%(n=14)$, and moved caudally in $21.6 \%(n=11)$ of the patients. However, neither the location of the tonsils nor any other parameters measured from pre- or postoperative MRI correlated with the patients' symptoms or surgical outcomes.

Conclusions No specific parameters on preoperative MRI evaluation were predictive of the outcome of surgery, emphasizing clinical examination in surgical decision-making. Furthermore, the postoperative MRI parameters did not correlate with the surgical outcomes. Thus, routine postoperative imaging is suggested only for patients with preoperatively diagnosed syringomyelia or worsening of symptoms.
\end{abstract}

Keywords Chiari malformation $\cdot$ MRI $\cdot$ Preoperative $\cdot$ Postoperative $\cdot$ Decompressive

Niina Salokorpi and Maria Suo-Palosaari contributed equally to this work.

This article is part of the Topical Collection on Pediatric Neurosurgery

Maria Suo-Palosaari

maria.suo-palosaari@ppshp.fi

1 Department of Diagnostic Radiology, Oulu University Hospital, Oulu and Research Unit of Medical Imaging, Physics, and Technology, Oulu University Hospital and University of Oulu, Kajaanintie 50, OYS, P.O. Box 50, 90029 Oulu, Finland

2 Department of Neurosurgery, Oulu University Hospital, Oulu and Research Unit of Clinical Neuroscience, Medical Research Center Oulu (MRC Oulu), Oulu University Hospital and University of Oulu, Oulu, Finland

3 Department of Children and Adolescents, Oulu University Hospital, Oulu and PEDEGO Research Unit, University of Oulu and Medical Research Center Oulu (MRC Oulu), Oulu, Finland

4 Department of Neurosurgery, Kuopio University Hospital, Kuopio and Institute of Clinical Medicine-Neurosurgery, University of Eastern Finland, Kuopio, Finland

\section{Introduction}

Chiari 1 (CM1) is the mildest form of the posterior fossa malformation of the Chiari spectrum [24]. In CM1, the cerebellar tonsils are considered to be located at least $5 \mathrm{~mm}$ below the foramen magnum $[4,13,31,36]$. However, in infants, the diagnostic threshold is considered to be at least $7 \mathrm{~mm}$ below the foramen magnum [6]. CM1 is a usual incidental finding in magnetic resonance imaging (MRI), and it is found in 0.24 $0.9 \%$ of the adult population $[28,38]$. The prevalence of CM1 in children is reported to be in general $1.0-3.6 \%[1,33]$ and $0.6-0.8 \%$ in purely asymptomatic children $[10,17]$. The subjective symptoms of CM1 vary from headache to weakness or paralysis of the limbs [4, 22]. No reliable parameters have been found in MRI studies that correlate with clinical symptoms [4].

Syringomyelia and scoliosis are considered to be associated with CM1 $[4,36]$. The prevalence of syringomyelia in 
patients with CM1 varies between 20 and 70\% [18, 33, 36]. The customary treatment for CM1 is surgical decompression [41]. However, not all patients will benefit from surgery [2, 25-27]. A wide variety of imaging parameters have been described for evaluating the severity of CM1 to aid in surgical decision-making and assessing surgical outcome $[3,4,16,25$, $27,31,36]$. However, reliable radiological parameters have not yet been found to evaluate which cases will benefit from surgery [4]. In some studies, the preoperative presence of syringomyelia was associated with better surgical outcomes, while in other studies, no significant difference was observed between the patients with or without syringomyelia $[4,18]$. Our aim was to determine which MRI findings could predict a favorable surgical outcome.

\section{Methods and materials}

\section{Patient population}

This retrospective study included all the patients operated on due to CM1 in Oulu University Hospital between 2004 and 2018 who had both preoperative and postoperative MRI images available. Patients operated on due to CM2 or stenosis of the foramen magnum without cerebellar tonsillar descent and patients with secondary CM1 due to craniosynostoses were excluded. During these 15 years, 59 patients were operated on due to CM1. For 51 patients, both pre- and postoperative images were available, and thus, they were included in this study. Patients were divided into three age groups: children [under 10 years of age $(n=19)$ ], adolescents [10-19 years old $(n=13)]$, and adults [over 19 years of age $(n=19)]$. The mean age of the children was $5.1 \pm 2.0$ years and that of the adolescents was $14.2 \pm 2.5$ years. The mean age of the adults was $41.5 \pm 14.1$ years. The cohort of the children comprised 12 boys and 7 girls. The cohort of the adolescents consisted of 3 male and 10 female patients and that of the adults consisted of 3 male and 16 female patients. A standard foramen magnum decompression (FMD) with resection of the $\mathrm{C} 1$ lamina and with either dissection of the dural outer layer (in 39 cases) or with dural opening and duraplasty (in 12 cases) was performed for everyone. The technique was chosen according to the surgeons' preferences. The cerebellar tonsils were left intact in all cases. Five patients whose subjective symptoms did not improve or worsened after the first surgery required reoperation. The postoperative results were evaluated after the second surgery in these patients. Thus, postoperative evaluation in all the patients was performed after their Chiari treatment was considered complete, and no new operations were planned. The mean follow-up time was 7 years and 1 month (range 18-179 months). At the last evaluation of the medical records, no patient needed further surgical treatment, although some patients had further follow-up visits scheduled.

\section{Magnetic resonance imaging}

The MRI scans were performed on either 1.5 or 3 T MRI scanners. The preoperative scans were made in Oulu University Hospital or the referring central hospitals, and the postoperative control scans were made in Oulu University Hospital. Standard sagittal T1-weighted sequences of the brain and both sagittal and axial T2weighted sequences of the cervical spine were included in all the patient scans. The preoperative and postoperative brain or cervical MRIs were retrospectively analyzed. For the postoperative measurements, the last available control brain or cervical MRI was used. The median time interval between the surgery and the index postoperative imaging was 29 months (range 3-108 months) in children, 37 months (range 7-78 months) in adolescents, and 14 months (range 1-142 months) in adults. In 31 patients, only one postoperative MRI was performed.

\section{Radiological measurements}

Seventeen different parameters were measured from the preoperative MRI and 11 from the postoperative MRI. The measured parameters are listed in Table 1, and the measurements are illustrated in Fig. 1. The diameter of the spinal cord was measured at the level of the syrinx's widest area if the patient had syringomyelia. The measurements were planned by a pediatric radiologist (MS-P, with 16 years' radiology experience), according to the radiological measurement methodology described by Tubbs et al. [37]. The measurements were conducted by two of the authors (M-PJ, radiology resident and JuN, radiologist), who were blinded to each other's measurements. The mean values of the MRI parameters were calculated from the measurements made by two of the authors (M-PJ and $\mathrm{JuN}$ ), and the interrater reliability was evaluated. Two methods were used to measure the cerebellar tonsils' descent below the McRae line in the preoperative imaging: the distance vertical to the McRae middle point (Fig. 1a, measurement 1) and the distance perpendicular to the McRae line (Fig. 1a, measurement 2). Postoperative tonsillar herniation could not be evaluated from the McRae line because the occipital bone had been removed from the skull base. Thus, tonsillar descent was evaluated by measuring the distance from the tonsillar tip to the line drawn through the synchondrosis of the second cervical vertebra (C2) (Fig. 1b, measurement 8 ) and parallel to the lower end plate of the $\mathrm{C} 2$ vertebra on the pre- and postoperative images to assess the dynamics of the tonsillar tip location (Fig. 1b, measurement 9). Altogether, the tonsillar tip location was measured using four different measurement methods on the preoperative MRI images and two measurement methods on the postoperative MRI images. 
Table 1 Preoperative MRI measurements in adults, adolescents, and children

\begin{tabular}{|c|c|c|c|}
\hline & $\begin{array}{l}\text { Adults } \\
\text { Mean (CI) }\end{array}$ & $\begin{array}{l}\text { Adolescents } \\
\text { Mean (CI) }\end{array}$ & $\begin{array}{l}\text { Children } \\
\text { Mean (CI) }\end{array}$ \\
\hline \multicolumn{4}{|l|}{ Cerebellar tonsils location in relation to: } \\
\hline$\cdot 1$ = McRae line (vertical to middle point), $\mathrm{mm}$ & $18.3(15.9-20.8)$ & $21.2(16.7-25.6)$ & $18.1(15.2-21.0)$ \\
\hline$\cdot 2=$ McRae line (perpendicular), $\mathrm{mm}$ & $15.1(12.1-18.2)$ & $20.0(15.2-24.7)$ & $16.8(13.6-19.9)$ \\
\hline$\bullet 8=\mathrm{C} 2$ synchondrosis, $\mathrm{mm}$ & $3.3(0.9-5.8)$ & $1.6(-2.9$ to 6.0$)$ & $-1.7(-5.0$ to 1.5$)$ \\
\hline$\cdot 9=\mathrm{C} 2$ vertebral end plate, $\mathrm{mm}$ & $12.5(10.1-14.9)$ & $8.8(4.9-12.7)$ & $5.4(2.3-8.4)$ \\
\hline $3=$ McRae line - obex, $\mathrm{mm}$ & $15.5(13.9-17.2)$ & $15.8(12.3-19.3)$ & $16.6(14.8-18.5)$ \\
\hline $4=$ Clivus canal angle, degrees & $153.2(148.6-157.9)$ & $150.5(140.2-160.8)$ & $156.0(151.0-161.0)$ \\
\hline $5=$ McRae line - tip of the dens, $\mathrm{mm}$ & $4.9(3.7-6.1)$ & $4.8(3.7-5.9)$ & $6.0(5.0-7.1)$ \\
\hline $6=$ Tentorium angle, $\mathrm{mm}$ & $41.7(39.8-43.6)$ & $40.0(37.7-42.3)$ & $41.1(39.5-42.8)$ \\
\hline $7=$ Occipital angle, degrees & $93.8(91.1-96.4)$ & $91.2(86.6-95.7)$ & $86.1(83.3-88.8)$ \\
\hline $10=$ Clivus length, $\mathrm{mm}$ & $39.6(37.2-42.1)$ & $37.3(34.9-39.6)$ & $34.0(32.5-35.5)$ \\
\hline $11=\mathrm{pB}-\mathrm{C} 2$ line, $\mathrm{mm}$ & $6.3(4.8-7.8)$ & $6.3(4.9-7.6)$ & $3.9(3.0-4.8)$ \\
\hline $12=$ Angle of the dens and the $\mathrm{C} 2$ vertebral end plate, degrees & $68.0(65.6-70.4)$ & $65.8(62.1-69.5)$ & $72.7(69.2-76.1)$ \\
\hline $13=$ Angle of the dens and the $\mathrm{C} 2$ synchondrosis, degrees & $77.3(74.2-80.3)$ & $73.7(70.1-77.4)$ & $76.9(74.3-79.6)$ \\
\hline $14=$ Odontoid process length, $\mathrm{mm}$ & $18.7(17.4-20.0)$ & $19.3(18.1-20.4)$ & $15.5(14.2-16.9)$ \\
\hline $15=$ Basioccipital length, $\mathrm{mm}$ & $20.2(18.0-22.3)$ & $22.1(20.1-24.1)$ & $17.6(16.7-18.6)$ \\
\hline $16=\mathrm{AP}$ diameter of syrinx, $\mathrm{mm}$ & $7.4(5.6-9.8)$ & $7.0(4.3-9.8)$ & $7.3(3.2-11.3)$ \\
\hline $17=\mathrm{AP}$ diameter of spinal cord, $\mathrm{mm}$ & $10.2(8.9-11.6)$ & $10.7(8.5-12.9)$ & $9.3(6.4-12.2)$ \\
\hline
\end{tabular}

$A P$ anteroposterior, $C I$ confidence interval, $p B-C 2$ line perpendicular distance to the basion- $C 2$ vertebral line

The number in front of each classification refers to the measurement method shown in Fig. 1

\section{Clinical symptoms and findings}

Data on symptoms and other clinical information were gathered from the Oulu University Hospital patient medical records. A neurosurgeon (NS, 16 years' neurosurgery experience) evaluated from the patient records what symptoms or findings had been the indications for the surgery. The surgical results were assessed as a change in these symptoms. According to the patients' medical records, the symptoms that were considered to be related to CM1 and thus were mentioned as indications for surgery were headache, neck pain, paresthesia, pain in limbs, limb weakness, balance problems, various visual disturbances, vertigo, and nausea. Syringomyelia and, in children, scoliosis appeared to be an indication for surgery in all cases if present. Preoperative motor and somatosensory evoked potentials, which were evaluated in 13 children, three adolescents, and only one adult patient, were not included in this study.

\section{Statistical analysis}

According to the interrater reliability analysis, there was moderate to excellent reliability in all but one measurement value between the two measurers. Poor reliability between the two measurers was only observed in analyzing the basilar invagination measurement (interclass correlation coefficient [ICC]
0.485). In the analysis of the other measurements, the ICC varied between 0.510 and 0.970 . An ANOVA test was used to evaluate the differences in the pre- and postoperative measurements between the surgical outcome groups. A chi-square test was used to evaluate whether preoperative categorical variables were associated with postoperative symptom improvement. A repeated measures ANOVA was used to compare pre- and postoperative measurements. Children, adolescents, and adults were analyzed separately except when clinical symptoms were studied due to relatively small number of cases per outcome group. A cerebellar tonsillar movement upward or downward was reported if the difference was more than $2 \mathrm{~mm}$. For all the tests, a significance level of $<0.05$ was used. All data were analyzed using IBM SPSS Statistics 25.0 software (IBM Corp., Armonk, NY, USA).

\section{Results}

According to their medical records, three of 19 (15.8\%) children and four of 13 (30.8\%) adolescents were asymptomatic but had either syringomyelia or/and scoliosis, which were considered to be indications for surgery. Three children had syringomyelia, and two had both syringomyelia and scoliosis. In adolescents, two had scoliosis, seven had syringomyelia, and two had both. There 

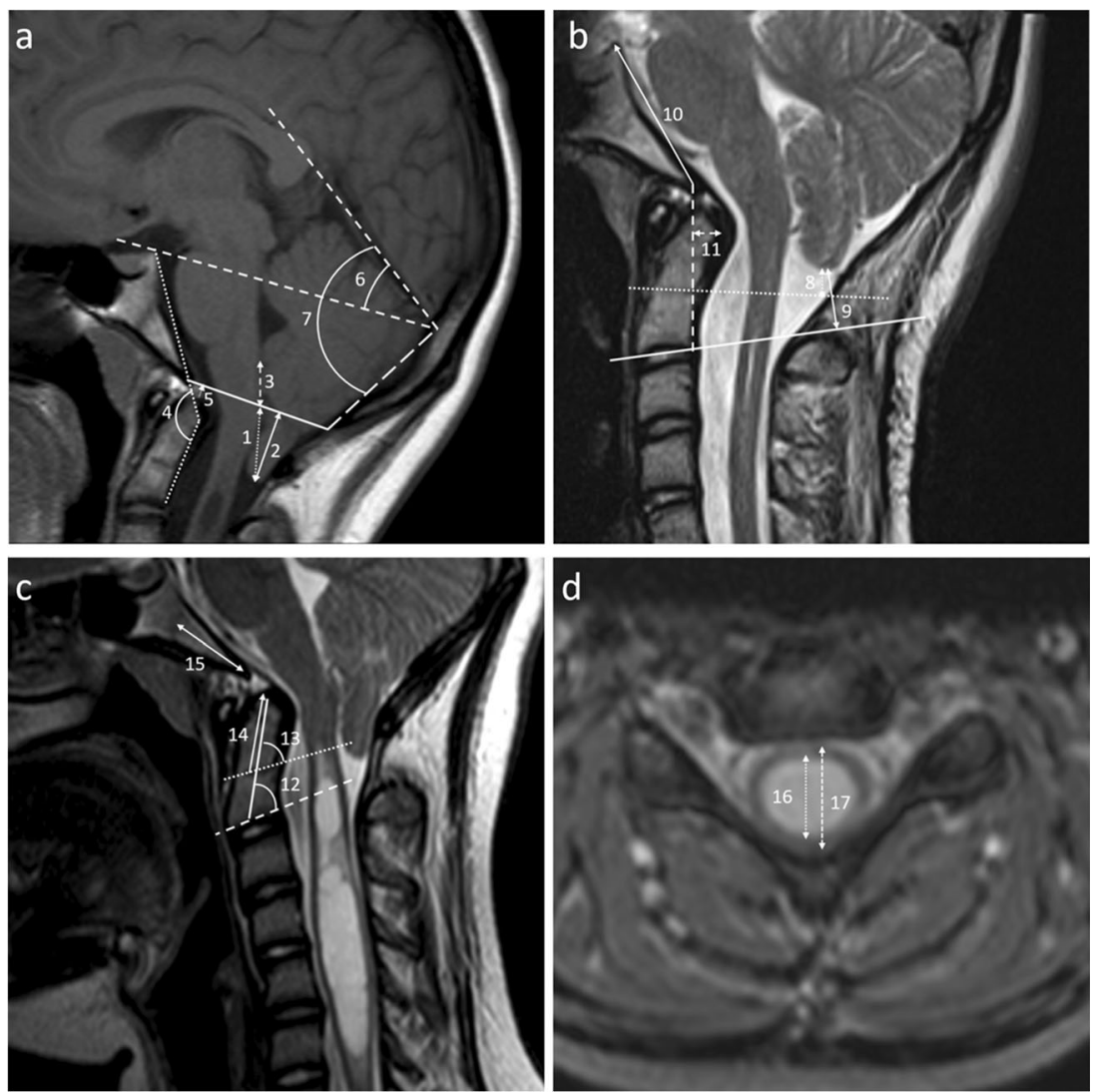

Fig. 1 Representative images of the measurements on the T1-weighted (T1W) midsagittal (a), T2-weighted (T2W) midsagittal (b and c), and $\mathrm{T} 2 \mathrm{~W}$ axial (d) planes. a $1=$ vertical distance of the tonsils to the midpoint of the McRae line; 2 = perpendicular distance of the tonsils below the McRae line; 3 = distance from the obex to the midpoint of the McRae line; 4 = angle between the line extending from the top of the dorsum sellae to the basion and the line between the inferodorsal portion of $\mathrm{C} 2$ to the most superodorsal part of the dens; $5=$ vertical distance of the tip of the dens to the McRae line; $6=$ angle between the tentorium cerebelli and a line from the internal occipital protuberance to the tuberculum sellae (Twining's line); 7 = angle between the tentorium cerebelli and a line from the internal occipital protuberance to the opisthion (slope of the tentorium cerebelli). $\mathbf{b} 8=$ perpendicular distance of the tonsils to the line drawn from the synchondrosis of the $\mathrm{C} 2$ vertebra; $9=$ perpendicular

were no asymptomatic adult patients. Syringomyelia was found in $42.1 \%(n=8)$ of the adults, in $69.2 \%(n=9)$ of the adolescents, and in $26.3 \%(n=5)$ of the children. The preoperative syrinx diameter varied from 3.1 to $12.3 \mathrm{~mm}$ in children, from 1.5 to $13.8 \mathrm{~mm}$ in adolescents, and from 3.8 to $9.8 \mathrm{~mm}$ in adults. Seventeen out of $22(77.3 \%)$ patients with syringomyelia were female. None of the adults had scoliosis, while two children $(10.5 \%)$ and four adolescents $(30.8 \%)$ had scoliosis. Only in one patient was scoliosis an incidental finding that did not influence decision-making. Scoliosis (scoliometer $>6$ degrees or Cobb angle $>20$ degrees) appeared to be an indication for CM1 surgery in five other cases. Syringomyelia was always considered an indication to perform surgery. distance of the tonsils to the line drawn from the end plate of the $\mathrm{C} 2$ vertebra; $10=$ clivus length (distance from the basion to the posterior clinoid process); 11 = perpendicular distance of the most posterior extent of the odontoid process at the dural interface to a line drawn between the basion and the posterior aspect of the $\mathrm{C} 2$ vertebral body (pB-C2 line). $\mathbf{c}$ $12=$ the angle between the line drawn from the end plate of the $\mathrm{C} 2$ vertebra and its intersection with a line drawn from the odontoid tip; 13 $=$ the angle between the line drawn from the synchondrosis of the $\mathrm{C} 2$ vertebra and its intersection with a line drawn from the odontoid tip; $14=$ length of the odontoid process; $15=$ basiocciput length (distance from the basion to the sphenooccipital synchondrosis). $\mathbf{d} 16=$ anteroposterior diameter of the syrinx; $17=$ anteroposterior diameter of the spinal cord at the level of the syrinx

\section{Preoperative radiological evaluation}

The MRI measurements of the children, adolescents, and adults were evaluated separately (Table 1). In the children, the cerebellar tonsils were located more caudally when measured from the $\mathrm{C} 2$ vertebral end plate compared to adults. The clivus length, the basioccipital length, the odontoid process length, the $\mathrm{pB}-\mathrm{C} 2$ line, and the occipital angle were smaller in children. However, the angle of the dens and the $\mathrm{C} 2$ vertebral end plate was bigger in children.

There was no statistically significant difference between the two different tonsillar location measurement methods taken from the McRae line (Fig. 1a, measurements 1 and 2). The tonsillar tip location perpendicular to the McRae line was on 
average $16.8 \mathrm{~mm}$ (range $7.7-30.9 \mathrm{~mm}$ ) in the children, $20.0 \mathrm{~mm}$ (range $10.6-41.7 \mathrm{~mm}$ ) in the adolescents, and $15.1 \mathrm{~mm}$ (range $5.3-30.0 \mathrm{~mm}$ ) in the adults. The tonsillar tip perpendicular location measured from the McRae line correlated well to the location measured from the $\mathrm{C} 2$ vertebra using both the synchondrosis and the end plate line $(r=0.771$ and $r$ $=0.741$, respectively, $p<0.001$ ).

\section{Postoperative radiological evaluation}

In the children, the postoperative measurements of the following parameters showed a statistically significant increase compared to the preoperative measurements: the angle of the dens and the $\mathrm{C} 2$ end plate, the basioccipital length, the clivus length, the odontoid process length, and the $\mathrm{pB}-\mathrm{C} 2$ line. In the adults, both the tonsillar location to the $\mathrm{C} 2$ end plate line and the tonsillar location to the $\mathrm{C} 2$ synchondrosis line increased. While the same tendency was observed in the children, it was not statistically significant. In the children, the adolescents, and the adults, the diameters of the syrinx decreased after the operation. Furthermore, the diameter of spinal cord decreased after the operation in both the adolescents and the adults. In the children, the diameter of spinal cord had a tendency of decreasing after the operation, but a statistically significant change was not observed. These measurement results are shown in detail in Table 2.

After the operation, the tonsils were located more caudally when measured perpendicular to the $\mathrm{C} 2$ end plate line in the adolescents with syringomyelia, $7.3 \mathrm{~mm}(2.9-11.7 \mathrm{~mm})$, compared to those without syringomyelia, $15.3 \mathrm{~mm}(5.8-24.9$ $\mathrm{mm}), p=0.042$. The opposite finding was observed in the adults where tonsils were located more caudally without syringomyelia, $6.2 \mathrm{~mm}(3.7-8.7 \mathrm{~mm})$ vs in the adults with syringomyelia $11.7 \mathrm{~mm}(6.3-17.0 \mathrm{~mm})(p=0.026)$ when measured perpendicular to the $\mathrm{C} 2$ synchondrosis line. The angle of the dens and the $\mathrm{C} 2$ synchondrosis was smaller in the adults without syringomyelia, 74.5 degrees (71.7-77.2 degrees), compared to those with syringomyelia, $80.1 \mathrm{~mm}$ (73.9-86.2 $\mathrm{mm}), p=0.043$. In the adolescents, the clivus canal angle was smaller on the preoperative imaging $(p=0.022)$ in the presence of syringomyelia. The same tendency was noticeable ( $p$ $=0.081$ ) in these patients postoperatively. No other significant differences were observed in the pre- or postoperative measurements between the patients with or without syrinxes. The preoperative size of the syrinx did not correlate with the change in the size of the syrinx at the first or the second follow-up imaging after surgery. The time interval between the surgery and the postoperative imaging did not correlate with the change in the size of the syrinx or the change in the position of the cerebellar tonsils relative to the $\mathrm{C} 2$ vertebral end plate or the C2 synchondrosis. In $90.9 \%(n=20)$ of the patients with syringomyelia, the size of the syrinx was smaller postoperatively than preoperatively. The syrinxes increased in size after the operation in two out of 22 patients $(9.1 \%)$ with syringomyelia. In one patient, the syrinx had increased at the first control scan and had decreased at the second control scan, remaining larger compared to the preoperative imaging (follow-up time 72 months). In this patient, there was a 13 months' time lapse between the last preoperative imaging and the surgery, leaving the possibility that the syrinx had already increased in size preoperatively. In the other patient, the syrinx had decreased at the first postoperative imaging and increased at the second follow-up imaging 11 months after the surgery.

Figure 2 shows the changes in the positions of the cerebellar tonsils relative to the $\mathrm{C} 2$ vertebral end plates after surgery. In most cases, the tonsils were located more cranially after surgery. The margin of error was considered to be $2 \mathrm{~mm}$ for a change of the cerebellar tonsils' location. The tonsils moved cranially postoperatively in $51.0 \%(n=26)$, did not change in $27.4 \%(n=14)$, and moved caudally in $21.6 \%(n=11)$ of the patients.

\section{Postoperative behavior of clinical symptoms, scoliosis, and syringomyelia}

In 46 patients, only one operation was performed, and in five patients (two children, two adolescents, and one adult), reoperation was performed. No patient required more than two operations. The postoperative results were evaluated after the treatment was considered complete, and no more operations were planned.

The surgical outcomes were evaluated, and the patients were divided into four subgroups according to the postoperative behavior of the preoperative clinical symptoms: resolved, improved, remained unchanged, or worsened. In the patients with scoliosis or syringomyelia who did not have subjective symptoms, the results of the surgery were estimated according to the changes in the syringomyelia and/or scoliosis measurements after the operation. In most of the patients, the subjective clinical symptoms that were indications for the surgery improved or resolved (Tables 3 and 4). One initially subjectively asymptomatic child, with scoliosis and severe syringomyelia being indications for surgery, had worsened scoliosis, and her syringomyelia did not improve after the surgery, which was performed when the patient was 14 years old (Table 3). This patient underwent surgery for shunting of the syrinx 1.5 years later. During the following 10 years, she progressively developed symptoms related to syringomyelia in spite of the decrease of the syrinx. None of the patients with scoliosis required surgery due to it; however, four out of six patients were treated with a scoliosis brace.

Due to the small sizes of the four subgroups concerning the behavior of the subjective clinical symptoms, scoliosis, or 
Table 2 The measurements that changed significantly after surgery when comparing preoperative and postoperative MRI

\begin{tabular}{|c|c|c|c|c|c|c|}
\hline & \multicolumn{2}{|l|}{ Children } & \multicolumn{2}{|l|}{ Adolescents } & \multicolumn{2}{|l|}{ Adults } \\
\hline & Mean difference $(\mathrm{CI})$ & $p$-value & Mean difference $(\mathrm{CI})$ & $p$-value & Mean difference $(\mathrm{CI})$ & $p$-value \\
\hline \multicolumn{7}{|l|}{ Cerebellar tonsils location, $\mathrm{mm}$} \\
\hline - $\mathrm{C} 2$ vertebral end plate & $4.4(-0.3,9.2)$ & 0.066 & $1.0(-3.0,5.0)$ & 0.597 & $3.8(1.7,6.0)$ & 0.002 \\
\hline •C2 synchondrosis & $4.1(-0.1,8.3)$ & 0.054 & $0.1(-4.5,4.7)$ & 0.967 & $5.4(2.3,8.5)$ & 0.002 \\
\hline $\begin{array}{l}\text { Angle of the dens and the } \mathrm{C} 2 \\
\text { vertebral end plate, degrees }\end{array}$ & $-4.5(-8.7,-0.2)$ & 0.040 & $-2.8(-6.0,-0.3)$ & 0.071 & $0.7(-1.6,3.0)$ & 0.538 \\
\hline Basioccipital length, mm & $3.7(2.3,5.1)$ & $<0.001$ & $1.0(-0.4,2.5)$ & 0.145 & $0.6(-0.9,2.2)$ & 0.406 \\
\hline Clivus length, mm & $4.3(2.6,6.0)$ & $<0.001$ & $1.0(-1.3,3.2)$ & 0.333 & $0.3(-1.3,2.0)$ & 0.699 \\
\hline Odontoid process length, $\mathrm{mm}$ & $2.9(1.6,4.2)$ & $<0.001$ & $0.5(0.0,1.1)$ & 0.048 & $0.8(-0.4,1.9)$ & 0.165 \\
\hline $\mathrm{pB}-\mathrm{C} 2$ line, $\mathrm{mm}$ & $2.3(1.3,3.2)$ & $<0.001$ & $0.2(-0.2,0.6)$ & 0.237 & $0.1(-0.9,1.1)$ & 0.823 \\
\hline Diameter of the spinal cord, $\mathrm{mm}$ & $-1.8(-4.1,0.4)$ & 0.091 & $-3.4(-5.6,-1.2)$ & 0.008 & $-2.5(-3.7,-1.4)$ & 0.001 \\
\hline Diameter of the syrinx, $\mathrm{mm}$ & $-3.8(-6.0,-1.6)$ & 0.009 & $-3.6(-6.1,-1.0)$ & 0.013 & $-4.0(-6.5,-1.6)$ & 0.006 \\
\hline
\end{tabular}

$C I$ confidence interval, $p B-C 2$ line perpendicular distance to the basion-C2 vertebral line

syringomyelia, the patients were divided into two outcome groups for statistical analysis: symptoms improved/resolved and symptoms remained unchanged/worsened (Table 4). Table 5 shows the clinical symptoms that were considered indications for surgery.

The preoperative diameter of the spinal cord at the syrinx level was smaller in the patients whose symptoms resolved or improved (mean difference $3.3 \mathrm{~mm}, 95 \%$ CI: $0.5-6.2 \mathrm{~mm}, p=$ 0.024). However, the preoperative size of the syrinx itself (Table 1, measurement 16) did not differ between the two surgical outcome groups. The preoperative presence of a syrinx or scoliosis was not associated with postoperative symptom improvement $(p=1.00)$. The postoperative movement of the cerebellar tonsils (perpendicular to the $\mathrm{C} 2$ end plate or the $\mathrm{C} 2$ synchondrosis) compared to the preoperative imaging was not associated with symptom improvement $(p=0.468$ and $p=$ 0.372 , respectively). Similarly, the change in the size of the syrinx after surgery was not associated with symptom improvement, $p=0.363$. There were no statistically significant

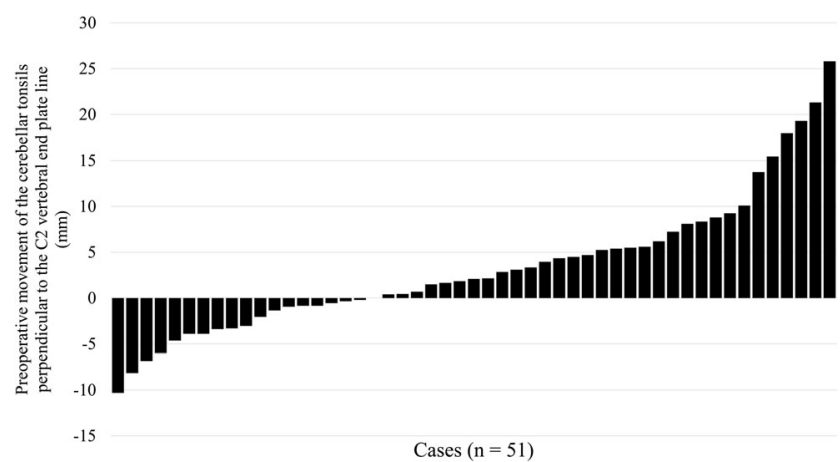

Fig. 2 Movement of the cerebellar tonsils in relation to the $\mathrm{C} 2$ vertebral end plate after surgery. A positive value means that the tonsils have moved upward differences between the two surgical outcome groups in any other measurement results.

All the children and all but one adolescent were operated with FMD without duraplasty, while in adults, duraplasty was done in over half of the operations. Thus, the effect of the operative method on surgical outcome in different age groups could not be statistically analyzed.

\section{Discussion}

In the present study, we could not define any single parameter measured on the preoperative MRI that would reliably predict change in the clinical symptoms after FMD surgery. This is in line with the previous studies $[4,11,14]$.

The cerebellar tonsils are reported to move during neck extension and flexion and during the cardiac cycle $[9,35]$. Thus, there could be a margin of error, which should be considered especially in borderline cases when tonsils are located only 5 to $6 \mathrm{~mm}$ below the foramen magnum. In the present study, in only three cases were the cerebellar tonsils located just 5-8 $\mathrm{mm}$ below the McRae line preoperatively. In all the other cases, the tonsils were located more caudally. All four methods used in this study to measure the cerebellar tonsils' descent were feasible and correlated well with each other. Thus, the postoperative change in the tonsillar location can be evaluated as the distance from the $\mathrm{C} 2$ vertebral end plate or the $\mathrm{C} 2$ synchondrosis.

Although the preoperative imaging parameters did not show a statistically significant correlation with the improvement of symptoms, the cerebellar tonsils moved more cranially after FMD surgery in half of the patients, which was a positive radiological result of the surgery. This is an especially interesting finding, since tonsillar coagulation was performed 
Table 3 Surgical outcomes in children, adolescents, and adults

\begin{tabular}{|c|c|c|c|c|c|c|}
\hline \multirow{2}{*}{$\begin{array}{l}\text { Symptoms and/or } \\
\text { Scoliosis }\end{array}$} & \multicolumn{2}{|c|}{ Children $n(\%)$} & \multicolumn{2}{|c|}{ Adolescents $n(\%)$} & \multicolumn{2}{|c|}{ Adults $n(\%)$} \\
\hline & $\begin{array}{l}\text { With } \\
\text { syrinx }\end{array}$ & $\begin{array}{l}\text { Without } \\
\text { syrinx }\end{array}$ & $\begin{array}{l}\text { With } \\
\text { syrinx }\end{array}$ & $\begin{array}{l}\text { Without } \\
\text { syrinx }\end{array}$ & $\begin{array}{l}\text { With } \\
\text { syrinx }\end{array}$ & $\begin{array}{l}\text { Without } \\
\text { syrinx }\end{array}$ \\
\hline Resolved & $1(20.0)$ & $6(42.9)$ & $2(22.2)$ & $1(25.0)$ & $1(12.5)$ & $2(18.2)$ \\
\hline Improved & $4(80.0)$ & $7(50.0)$ & $5(55.6)$ & $3(75.0)$ & $6(75.0)$ & $7(63.6)$ \\
\hline Remained unchanged & 0 & $1(7.1)$ & $1(11.1)$ & 0 & $1(12.5)$ & $2(18.2)$ \\
\hline Worsened & 0 & 0 & $1(11.1)$ & 0 & 0 & 0 \\
\hline
\end{tabular}

only for one patient. Previously, it has been reported that in most cases, the cerebellar tonsils moved upward or backward after posterior fossa decompression [40]; in the same study, the maximal syrinx/spinal cord ratio and the syrinx length were demonstrated to improve after surgery. In addition, the postoperative tonsillar movement cranially was shown to correlate with the syrinx/spinal cord ratio [40]. We did not find a statistically significant correlation between symptom improvement and changes in syrinx size or tonsillar movement after surgery. The change in the size of the syrinx did not correlate to the tonsillar movement postoperatively. In three asymptomatic children and four asymptomatic adolescents, syringomyelia with or without scoliosis was considered to be a sufficient finding to make a decision for an operation, which was in accordance with the standard practice [41]. Neither changes in syrinx size nor changes in tonsillar location correlated with the time lapse between the surgery and the postoperative MRI, despite the big differences in follow-up times between the patients.

In the children, the clivus canal angle, the angle of the dens and the $\mathrm{C} 2$ end plate, the basioccipital length, the clivus length, the odontoid process length, the pB-C2 line, and the syrinx significantly changed postoperatively. However, the changes in some of these parameters may be explained by the child's head growth, since the time between the preoperative and postoperative imaging was on average 48 months (range 8 months -9 years and 5 months). Skull growth could explain the difference between some linear measurement results when comparing preoperative MRI to postoperative imaging in children. In the adults, the tonsillar location in relation to the $\mathrm{C} 2$ end plate line and the $\mathrm{C} 2$ synchondrosis line, as well as the diameters of the spinal cord and the syrinx, changed after surgery. In the adolescents, only the odontoid process length and the diameters of the spinal cord and the syrinx changed after surgery.

In our study, $42.1 \%$ of the adults, $69.2 \%$ of the adolescents, and $26.3 \%$ of the children had preoperative syringomyelia. The prevalence of syringomyelia was in accordance with previous studies, which showed the presence of syringomyelia in $20-70 \%$ of cases $[8,18,33,36]$. Interestingly, syringomyelia predominated in female patients, being present in $52 \%$ of females and only $28 \%$ of males. Most of the syrinxes decreased postoperatively in all age groups of the patients. Only one patient in this population required syrinx shunting. Although Hekman et al. found a correlation between the presence of a syrinx and postoperative symptom improvement [15], we did not find this correlation, which is in concordance with the studies by Atchley et al. and Kalb et al. [4, 18]. Correlation of a decrease in the size of the spinal cord diameter with symptom improvement after surgery has been shown previously [12]. In our study, there was a tendency for symptom improvement in patients whose spinal cord size at the level of the syrinx was smaller preoperatively. However, due to the few patients included (only three patients with syringomyelia whose symptoms did not improve in our study), conclusions cannot be drawn with certainty.

The prevalence of scoliosis is reported to vary between 13 and $36 \%$ in patients with CM1 [8, 30, 34]. In the present study, $10.5 \%$ of the children and $30.8 \%$ of the adolescents had scoliosis, while scoliosis was not mentioned in any medical records of the adults. The prevalence of scoliosis has been shown to be higher in CM1 patients with syringomyelia [30]. However, in our study, we did not find this correlation, probably due to small number of patients. We also found no difference in postoperative symptom improvement between patients with or without scoliosis. In a previous study, scoliosis
Table 4 Surgical outcomes in patients with subjective symptoms

\begin{tabular}{lllll}
\hline Symptoms & Children $n(\%)$ & Adolescents $n(\%)$ & Adults $n(\%)$ & Total $n(\%)$ \\
\hline Resolved & $7(43.8)$ & $2(22.2)$ & $3(15.8)$ & $12(27.3)$ \\
Improved & $8(50.0)$ & $6(66.7)$ & $13(68.4)$ & $27(61.4)$ \\
Remained unchanged & $1(6.3)$ & $1(11.1)$ & $3(15.8)$ & $5(11.4)$ \\
Worsened & 0 & 0 & 0 & 0 \\
\hline
\end{tabular}


Table 5 Subjective clinical symptoms (grouped for simplification) considered indications for surgery according to medical records

\begin{tabular}{|c|c|c|c|c|c|c|c|c|}
\hline & \multicolumn{2}{|l|}{ Children $n(\%)$} & \multicolumn{2}{|c|}{ Adolescents $n(\%)$} & \multicolumn{2}{|l|}{ Adults $n(\%)$} & \multicolumn{2}{|l|}{ Total $n(\%)$} \\
\hline & $\begin{array}{l}\text { Present } \\
\text { preoperatively }\end{array}$ & $\begin{array}{l}\text { Improved/ } \\
\text { resolved }\end{array}$ & $\begin{array}{l}\text { Present } \\
\text { preoperatively }\end{array}$ & $\begin{array}{l}\text { Improved/ } \\
\text { resolved }\end{array}$ & $\begin{array}{l}\text { Present } \\
\text { preoperatively }\end{array}$ & $\begin{array}{l}\text { Improved/ } \\
\text { resolved }\end{array}$ & $\begin{array}{l}\text { Present } \\
\text { preoperatively }\end{array}$ & $\begin{array}{l}\text { Improved/ } \\
\text { resolved }\end{array}$ \\
\hline Headache & $14(73.7)$ & $13(92.9)$ & $9(69.2)$ & $6(66.6)$ & $15(78.9)$ & $13(86.7)$ & $38(74.5)$ & $32(84.2)$ \\
\hline $\begin{array}{l}\text { Motor or sensory } \\
\text { disturbances in the limbs }\end{array}$ & $3(15.8)$ & $3(100.0)$ & $3(23.1)$ & $3(100.0)$ & $12(63.2)$ & $10(83,3)$ & $18(35.3)$ & $16(88.9)$ \\
\hline Balance disturbances & $1(5.3)$ & $1(100.0)$ & $2(15.4)$ & $2(100.0)$ & $5(26.3)$ & $4(80.0)$ & $8(15.7)$ & $7(87.5)$ \\
\hline Visual disturbances & $2(10.5)$ & $2(100.0)$ & $1(7.7)$ & $1(100.0)$ & 0 & $\mathrm{~N} / \mathrm{A}$ & $3(9.7)$ & $3(100.0)$ \\
\hline Other symptoms ${ }^{\mathrm{a}}$ & $1(3.2)$ & $1(100.0)$ & 0 & $\mathrm{~N} / \mathrm{A}$ & $1(5.0)$ & $1(100.0)$ & $2(3.9)$ & $2(100.0)$ \\
\hline
\end{tabular}

N/A not applicable

${ }^{\text {a }}$ Other symptoms were fatigue in one adult patient and vomiting in one child

with a Cobb angle $<20$ degrees was associated with better postoperative stability/improvement [20].

Ladner et al. reported that a pB-C2 line length over $3 \mathrm{~mm}$, reflecting ventral canal encroachment on preoperative MRI, was associated with postoperative symptom improvement [21]. In contrast, Greenberg et al. found the $\mathrm{pB}-\mathrm{C} 2$ line length to be insignificant [14]. In our study, this measurement did not correlate with symptom improvement $(p=0.593)$, and it increased postoperatively only in children. It has been reported that after posterior fossa decompression, the $\mathrm{pB}-\mathrm{C} 2$ line increases probably due to lower pressure on the ventral dura [5]. Like previous studies, we did not find a statistically significant association with other imaging parameters concerning the clivus canal angle, the dens angle, the tonsillar location, the obex position, the tentorial angle, and the presence of a syrinx or scoliosis $[4,11,14]$.

The postoperative clinical results were considered good in almost all the cases. In $12 \%$ of the patients, there was no improvement in the subjective symptoms. In other studies, approximately $30-40 \%$ of patients' symptoms did not improve, or the improvement was quite small $[2,12,14,18$, $25,27]$. Patients may also experience symptom recurrence after a long follow-up period [26]. We cannot directly compare our surgical outcome to previous studies, as we only evaluated the changes in the symptoms that were considered to be an indication for surgery. Patients might also have had other symptoms that were relieved after surgery, but preoperatively they were either not mentioned in the medical records or they were not considered to be related to CM1.

The decision for CM1 surgery should be based on clinical evaluation rather than imaging findings only. Mild symptomatic CM1 may improve spontaneously in both adults and children $[7,19]$, although greater spontaneous symptom improvement is more likely to happen in children [19]. Asymptomatic CM1 often remains asymptomatic $[6,22,23,39]$. In a study in which CM1 patients were followed radiologically without any surgery, no significant worsening in asymptomatic patients without syringomyelia was found [39]. According to another study, symptom development did not seem to correlate with radiological changes, and routine imaging follow-up in asymptomatic cases without syringomyelia was not considered reasonable [39]. The potential benefits of surgery and MRI follow-up must always outweigh the potential disadvantages. Because the postoperative symptom improvement of CM1 patients did not correlate with any imaging parameter in our study, we do not recommend routine follow-up imaging in cases with symptom improvement. Although syringomyelia can often remain asymptomatic [29], it can also be associated with severe symptoms, and previously asymptomatic patients may have a sudden onset of symptoms [32]. Therefore, we recommend follow-up imaging in CM1 patients with syringomyelia.

Our study has a few limitations. The sample size was quite small when the patients were divided into four groups according to surgical outcome. Therefore, the patients were divided into two different outcome groups for the final statistical analyses. A small sample size can lead to bias, and the significance of chance may be emphasized. Poor reliability between the two measurers was observed in the measurement of the tip of the dens location, which can be considered a limitation for making conclusions about the significance of this particular finding. The patients' surgical outcomes were retrospectively evaluated based on their medical records, which may cause inaccuracy. Due to the retrospective nature of this study and the relatively small sample size, the clinical symptoms could not be scored. In addition, we did not undertake any multiparametric analysis of the symptoms. Thus, some MRI parameters or combinations of parameters could still be predictive of the easing of symptoms. Further prospective studies are needed to answer these questions.

At our institution, until the last few years neither cerebrospinal fluid (CSF) flow imaging by cine MRI nor intraoperative ultrasound was used routinely in Chiari patients. There was only a visual, subjective evaluation of the CSF flow 
restoration at the level of foramen magnum during the surgery. In the patients without duraplasty, the dural dissection always resulted in such thinning of dura that the movement of cerebellar tonsils and the restoration of CSF flow were visually confirmed. Nowadays, the CSF cine sequence is included in the MRI protocol, and intraoperative ultrasound is used whenever necessary.

\section{Conclusions}

In half of the operated CM1 patients, the cerebellar tonsils shifted upward, with the distance to the $\mathrm{C} 2$ synchondrosis or the $\mathrm{C} 2$ end plate being equally feasible for evaluation of these changes. Also, the syrinxes decreased in size postoperatively in most patients. However, we found no reliable MRI parameters that could predict surgical outcome in CM1 patients from the preoperative imaging nor parameters that could reflect the surgical outcome from the postoperative imaging. Patient selection for CM1 surgery should be considered thoroughly based on clinical symptoms rather than any single radiological parameter after CM1 diagnosis established on MRI. Postoperative MRI imaging after Chiari operations has no benefit in cases without syringomyelia or suspected complications.

Author contribution Miro-Pekka Jussila: Conceptualization, data curation, formal analysis, investigation, visualization, writing - original draft, and writing - review and editing. Juho Nissilä: Conceptualization, data curation, investigation, writing - original draft, and writing - review and editing. Minna Vakkuri: Conceptualization, data curation, and investigation. Päivi Olsén: Conceptualization and writing - review and editing. Jaakko Niinimäki: Writing - review and editing. Ville Leinone: Conceptualization and writing-review and editing. Willy Serlo: Conceptualization and writing - review and editing. Niina Salokorpi: Conceptualization, data curation, formal analysis, investigation, visualization, writing - original draft, writing - review and editing, and supervision. Maria Suo-Palosaari: Data curation, formal analysis, investigation, visualization, writing - original draft, writing — review and editing, and supervision

Funding Open access funding provided University of Oulu including Oulu University Hospital. MPJ received a research grant from the Radiological Society of Finland and the Arvo and Lea Ylppö Foundation for this study. The sponsors had no role in the design or conduct of this research.

\section{Declarations}

Ethics approval The study was performed in accordance with the ethical standards of Oulu University Hospital and with the 1964 Helsinki Declaration and its later amendments or comparable ethical standards. Formal consent of the participants was not required since this was an observational study with no interference with the patients' treatment and follow-up protocols. As a register study, no formal evaluation by the Ethics Review Committee was needed.
Conflict of interest The authors declare no competing interests.

Open Access This article is licensed under a Creative Commons Attribution 4.0 International License, which permits use, sharing, adaptation, distribution and reproduction in any medium or format, as long as you give appropriate credit to the original author(s) and the source, provide a link to the Creative Commons licence, and indicate if changes were made. The images or other third party material in this article are included in the article's Creative Commons licence, unless indicated otherwise in a credit line to the material. If material is not included in the article's Creative Commons licence and your intended use is not permitted by statutory regulation or exceeds the permitted use, you will need to obtain permission directly from the copyright holder. To view a copy of this licence, visit http://creativecommons.org/licenses/by/4.0/.

\section{References}

1. Aitken LA, Lindan CE, Sidney S, Gupta N, Barkovich AJ, Sorel M, Wu YW (2009) Chiari type I malformation in a pediatric population. Pediatr Neurol 40(6):449-454

2. Aliaga L, Hekman KE, Yassari R, Straus D, Luther G, Chen J, Sampat A, Frim D (2012) A novel scoring system for assessing Chiari malformation type I treatment outcomes. Neurosurgery 70(3):656-664

3. Alperin N, Loftus JR, Bagci AM, Lee SH, Oliu CJ, Shah AH, Green BA (2017) Magnetic resonance imaging-based measures predictive of short-term surgical outcome in patients with Chiari malformation Type I: a pilot study. J Neurosurg Spine 26(1):28-38

4. Atchley TJ, Alford EN, Rocque BG (2020) Systematic review and meta-analysis of imaging characteristics in Chiari I malformation: does anything really matter? Childs Nerv Syst 36(3):525-534

5. Bonney PA, Maurer AJ, Cheema AA, Duong Q, Glenn CA, SafaviAbbasi S, Stoner JA, Mapstone TB (2016) Clinical significance of changes in $\mathrm{pB}-\mathrm{C} 2$ distance in patients with Chiari Type I malformations following posterior fossa decompression: a singleinstitution experience. J Neurosurg Pediatr 17(3):336-342

6. Chatrath A, Marino A, Taylor D, Elsarrag M, Soldozy S, Jane JA (2019) Chiari I malformation in children - the natural history. Childs Nerv Syst 35(10):1793-1799

7. Chavez A, Roguski M, Killeen A, Heilman C, Hwang S (2014) Comparison of operative and non-operative outcomes based on surgical selection criteria for patients with Chiari I malformations. J Clin Neurosci Off J Neurosurg Soc Australas 21(12):2201-2206

8. Ciaramitaro P, Ferraris M, Massaro F, Garbossa D (2019) Clinical diagnosis - part I: what is really caused by Chiari I. Childs Nerv Syst 35(10):1673-1679

9. Cousins J, Haughton V (2009) Motion of the cerebellar tonsils in the foramen magnum during the cardiac cycle. AJNR Am J Neuroradiol 30(8):1587-1588

10. Dangouloff-Ros V, Roux CJ, Boulouis G, Levy R, Nicolas N, Lozach C, Grevent D, Brunelle F, Boddaert N, Naggara O (2019) Incidental brain MRI findings in children: a systematic review and meta-analysis. AJNR Am J Neuroradiol 40(11):1818-1823

11. Deng X, Wu L, Yang C, Tong X, Xu Y (2013) Surgical treatment of Chiari I malformation with ventricular dilation. Neurol Med Chir (Tokyo) 53(12):847-852

12. Furtado SV, Thakar S, Hegde AS (2011) Correlation of functional outcome and natural history with clinicoradiological factors in surgically managed pediatric chiari i malformation. Neurosurgery 68(2):319-328

13. Gad KA, Yousem DM (2017) Syringohydromyelia in patients with Chiari I malformation: a retrospective analysis. Am J Neuroradiol 38(9):1833-1838 
14. Greenberg JK, Yarbrough CK, Radmanesh A, Godzik J, Yu M, Jeffe DB, Smyth MD, Park TS, Piccirillo JF, Limbrick DD (2015) The Chiari severity index: a preoperative grading system for Chiari malformation type 1. Neurosurgery 76(3):279-285

15. Hekman KE, Aliaga L, Straus D, Luther A, Chen J, Sampat A, Frim D (2012) Positive and negative predictors for good outcome after decompressive surgery for Chiari malformation type 1 as scored on the Chicago Chiari Outcome Scale. Neurol Res 34(7):694-700

16. Iskandar BJ, Quigley M, Haughton VM (2004) Foramen magnum cerebrospinal fluid flow characteristics in children with Chiari I malformation before and after craniocervical decompression. J Neurosurg 101(2 Suppl):169-178

17. Jansen PR, Dremmen M, van Den Berg A, Dekkers IA, Blanken LME, Muetzel RL, Bolhuis K, Mulder RM, Kocevska D, Jansen TA et al (2017) Incidental findings on brain imaging in the general pediatric population. N Engl J Med 377(16):1593-1595

18. Kalb S, Perez-Orribo L, Mahan M, Theodore N, Nakaji P, Bristol RE (2012) Evaluation of operative procedures for symptomatic outcome after decompression surgery for Chiari type I malformation. J Clin Neurosci 19(9):1268-1272

19. Killeen A, Roguski M, Chavez A, Heilman C, Hwang S (2015) Non-operative outcomes in Chiari I malformation patients. J Clin Neurosci Off J Neurosurg Soc Australas 22(1):133-138

20. Krieger MD, Falkinstein Y, Bowen IE, Tolo VT, Mccomb JG (2011) Scoliosis and Chiari malformation type I in children. J Neurosurg Pediatr 7(1):25-29

21. Ladner TR, Dewan MC, Day MA, Shannon CN, Tomycz L, Tulipan N, Wellons JC (2015) Evaluating the relationship of the pB-C2 line to clinical outcomes in a 15-year single-center cohort of pediatric Chiari I malformation. J Neurosurg Pediatr 15(2):178188

22. Langridge B, Phillips E, Choi D (2017) Chiari malformation type 1: a systematic review of natural history and conservative management. World Neurosurg 104:213-219

23. Leon TJ, Kuhn EN, Arynchyna AA, Smith BP, Tubbs RS, Johnston JM, Blount JP, Rozzelle CJ, Oakes WJ, Rocque BG (2019) Patients with "benign" Chiari I malformations require surgical decompression at a low rate. J Neurosurg Pediatr 23(4):498-506

24. McClugage SG, Oakes WJ (2019) The Chiari I malformation. J Neurosurg Pediatr 24(3):217-226

25. McGirt MJ, Atiba A, Attenello FJ, Wasserman BA, Datoo G, Gathinji M, Carson B, Weingart JD, Jallo GI (2008) Correlation of hindbrain CSF flow and outcome after surgical decompression for Chiari I malformation. Childs Nerv Syst 24(7):833-840

26. McGirt MJ, Attenello FJ, Atiba A, Garces-Ambrossi G, Datoo G, Weingart JD, Carson B, Jallo GI (2008) Symptom recurrence after suboccipital decompression for pediatric Chiari I malformation: analysis of 256 consecutive cases. Childs Nerv Syst 24(11):13331339

27. McGirt MJ, Nimjee SM, Fuchs HE, George TM (2006) Relationship of cine phase-contrast magnetic resonance imaging with outcome after decompression for Chiari I malformations. Neurosurgery 59(1):140-146

28. Morris Z, Whiteley WN, Longstreth WT Jr, Weber F, Lee YC, Tsushima Y, Alphs H, Ladd SC, Warlow C, Wardlaw JM et al
(2009) Incidental findings on brain magnetic resonance imaging: systematic review and meta-analysis. BMJ 339:b3016

29. Nishizawa S, Yokoyama T, Yokota N, Tokuyama T, Ohta S (2001) Incidentally identified syringomyelia associated with Chiari I malformations: is early interventional surgery necessary? Neurosurgery 49(3):637-641

30. Noureldine MHA, Shimony N, Jallo GI, Groves ML (2019) Scoliosis in patients with Chiari malformation type I. Childs Nerv Syst 35(10):1853-1862

31. Poretti A, Ashmawy R, Garzon-Muvdi T, Jallo GI, Huisman TAGM, Raybaud C (2016) Chiari type 1 deformity in children: pathogenetic, clinical, neuroimaging, and management aspects. Neuropediatrics 47(5):293-307

32. Schneider B, Birthi P, Salles S (2013) Arnold-Chiari 1 malformation type 1 with syringohydromyelia presenting as acute tetraparesis: a case report. J Spinal Cord Med 36(2):161-165

33. Strahle J, Muraszko KM, Kapurch J, Bapuraj JR, Garton HJL, Maher CO (2011) Chiari malformation Type I and syrinx in children undergoing magnetic resonance imaging. J Neurosurg Pediatr 8(2):205-213

34. Strahle J, Smith BW, Martinez M, Bapuraj JR, Muraszko KM, Garton HJL, Maher CO (2015) The association between Chiari malformation Type I, spinal syrinx, and scoliosis. J Neurosurg Pediatr 15(6):607-611

35. Tubbs RS, Kirkpatrick CM, Rizk E, Chern JJ, Oskouian RJ, Oakes WJ (2016) Do the cerebellar tonsils move during flexion and extension of the neck in patients with Chiari I malformation? A radiological study with clinical implications. Childs Nerv Syst 32(3): 527-530

36. Tubbs RS, Lyerly MJ, Loukas M, Shoja MM, Oakes WJ (2007) The pediatric Chiari I malformation: a review. Childs Nerv Syst 23(11):1239-1250

37. Tubbs RS, Wellons JC, Blount JP, Grabb PA, Oakes WJ (2003) Inclination of the odontoid process in the pediatric Chiari I malformation. J Neurosurg 98(1):43-49

38. Vernooij MW, Ikram MA, Tanghe HL, Vincent AJPE, Hofman A, Krestin GP, Niessen WJ, Breteler MMB, Van Der Lugt A (2007) Incidental findings on brain MRI in the general population. N Engl J Med 357(18):1821-1828

39. Whitson WJ, Lane JR, Bauer DF, Durham SR (2015) A prospective natural history study of nonoperatively managed Chiari I malformation: does follow-up MRI surveillance alter surgical decision making? J Neurosurg Pediatr 16(2):159-166

40. Xie D, Qiu Y, Sha S, Liu Z, Jiang L, Yan H, Chen L, Shi B, Zhu Z (2014) Syrinx resolution is correlated with the upward shifting of cerebellar tonsil following posterior fossa decompression in pediatric patients with Chiari malformation type I. Eur Spine J 24(1):155161

41. Youmans JR, Winn HR (2011) Youmans neurological surgery, vol 2. Elsevier Saunders, Philadelphia, pp 1918-1927

Publisher's note Springer Nature remains neutral with regard to jurisdictional claims in published maps and institutional affiliations. 